\title{
Three critical factors and their influence on the spread of microbiological waterborne diseases in sub Saharan countries (with special emphasis on cholera)
}

\author{
N. L. Musekene, M. Nepfumbada, P. Kempster, A. Kühn \\ \& H. van Niekerk \\ Department of Water Affairs and Forestry, Pretoria, South Africa
}

\begin{abstract}
The magnitude of microbiological epidemic outbreaks has reached alarming proportions within recent years. The hardest hit by these diseases are sub Saharan African countries. Outbreaks of acute intestinal bacterial infection caused by the bacterium Vibrio cholerae have claimed a greater percentage of lives in sub Saharan countries than the rest of the world combined, particularly women and children. While technological advancements to detect these micro pathogenic organisms are at their peak, outbreaks continue to plunder humanity in different communities.

Although the severity and the extent of consequences posed by such organisms are known and have been quantified more often, the fundamental background is that there are critical factors that exacerbate the spread of cholera amongst these countries. Poverty, the lack of a proper water supply and sanitation, the basic hygiene practice and absence of health systems need to be addressed in order to catalyze solutions to the growing problem.

This paper focuses mainly on reviewing the status of cholera and the identification of homogenous attributes within the sub Saharan African countries, which are influencing the spread of such diseases. This article proposes a containment programme in order for sustainable development to take place in the region.
\end{abstract}




\section{Introduction}

In the early 1700's, the pioneer of Microbiology, a Dutch Scientist Antonie Van Leeuwenhoek, first demonstrated the existence of minute life forms which where invisible to naked eyes. It was in the early $19^{\text {th }}$ century that a French scientist Fracastro and other scientists like Agostino Bassi (1773-1856) who discovered that certain microbes cause diseases, when he proved in 1835 that silkworm disease was a result of mould infection [1]. After that period many scientific works were done by scientists like Burkley, Joseph Lister (1827-1912), Robert Kock (1843-1910), Jacob Henley (1809-1855) and a French Scientist Louis Pasteur who showed that certain microbes like those in milk can actually be destroyed through the process of pasteurization (Heating of milk) [1]. New discoveries advanced to discover new diseases and emerging pathogens like Cryptosporidium, Salmonella, Shigella, Gastroenteritis etc.

The magnitude of outbreaks of the cholera epidemic has reached alarming proportions within the recent years. The region hardest hit by this acute intestinal bacterial infection caused by Vibrio cholerae is the sub Saharan countries. This type of bacterial infection by the 01 biotype El Tor (Inaba or Ogawa) had not been known to the world until it's seventh outbreak in Celebes (Suliwesi) Indonesia in 1961. Rapid spread of this disease then affected many countries in Eastern Asia and reached Bangladesh in 1963, then proceeded to India in 1964 $[2,3]$.

The first outbreak of cholera in Africa was in 1970, when West Africa was attacked. After that cholera cases have been reported throughout the continent including the Comoros Islands, Madagascar and Zanzibar. Severe cases took place in most central African countries especially those with poor water supply, poor sanitation and poverty. New cases of cholera are being reported in sub Saharan Africa almost everyday. Cholera is endemic in sub Saharan countries and the death cases are high.

\section{Aim and objectives}

The aim of this paper is to:

- Review the severity and extent of cholera outbreaks in sub Saharan countries.

- Address three critical factors that influence the spread of Cholera.

\section{Methodology}

Different methods were used to carry out the study. A combination of qualitative and quantitative was used. A Literature review formed the foundation of the primary data. Data on Communicable Disease Surveillance and Responses (CDSR) was obtained from World Health Organization (WHO) daily updates reported from 2001/2, whereas South African data and updates were obtained from Department of Health, Kwazulu-Natal (RSA). The Case Fatality Rate (CFR) was calculated using the following formula: 


$$
\mathrm{CFR}=\frac{\text { Number of Death Cases }}{\text { Total number of Cholera Cases }} \quad \mathrm{X} \quad \underline{\text { Percentage }}
$$

\section{Facts about cholera}

Cholera is a waterborne disease that originated in the Ganges River Delta of the Asian subcontinent, where it had been endemic for many centuries. Recently, cholera has been endemic to more than eighty countries worldwide and causes over 120000 deaths per year. Cholera is an acute intestinal infection caused by ingestion of contaminated food or water containing the bacterium Vibrio cholerae [3]. Cholera has been labeled a "poor man's disease" because of it being endemic to poor sanitation areas, where proper hygiene is not adhered to and where there is poor water supply. Cholera is more rife in tropical regions and that may be the reason why it is also termed a tropical disease.

The recent seventh pandemic (worldwide epidemic) of cholera that has surfaced in South Africa is caused by two serotypes of the agglutinating 01 (biotype El Tor) strain of Vibrio cholerae namely Ogawa and Inaba. The WHO identified the threat of the $8^{\text {th }}$ pandemic caused by previously unrecognized serogroup of Vibrio cholerae, which began in Bangladesh and India in 1992, i.e. NAG strain 0139, or the Bengal strain. The new 0139 strain is the only NAG strain that causes epidemic cholera, but that has not yet reached South Africa [3].

Cholera is spread, as are most other viral and bacterial diarrhoeal diseases, by contaminated water and food, i.e. the faecal oral route. Diarrhoeal disease can, therefore, occur whenever drinking water or food is contaminated with faecal material and whenever sanitation and hygiene are inadequate or compromised. The ever-present role of flies and other vectors through the faecal oral route must be kept in mind. It is rare that cholera would be transmitted through direct person-to-person contact however, the possibility cannot be entirely ruled out. Contaminated water supply, poor sanitation and lack of personal hygiene therefore, cause a sudden cholera breakout.

Although many people believe that certain cultural practices, such as social and religious events at venues without proper sanitation and safe water supply facilities, where food is prepared on a large scale and the migratory movement of people commuting over the long distances between home and workplace, can lead to the spread of disease to previous uninfected areas, major cholera outbreaks are not as a result of that. Also bearing in mind that there have been cases where the cholera outbreak was reported in areas about two thousand kilometers apart within a period of less than four hours, which leaves most questions to be answered if commuting has to be blamed.

Cholera infection is often mild and self-limited. It is acquired primarily by ingesting contaminated water or food. Mild and /or symptomatic cases of cholera far outnumber severe cases. Severe cases begin with the explosive onset of frequent, watery stools with appearance of 'rice water' and vomiting may also occur. These initial symptoms usually occur 2-3 days after exposure to cholera. If left untreated, an infected individual with severe symptoms becomes dehydrated, with abnormally low blood pressure, subnormal temperature, muscle cramps, 
decreased urine output, shock and eventually coma. Immunodeficiency and those with HIV/AIDS are a highly sensitive group. Persons with severe cases respond dramatically to simple fluid- and electrolyte-replacement therapy. Fluidelectrolyte balance can be assisted by drinking fruit juices, caffeine-free soft drinks, and eating salted crackers.

\section{Cholera overview in sub Saharan countries 2001/2}

Different Health Ministries have reported a total of 235181 cholera cases to the WHO from 2001 to November 2002 in sub Saharan countries. South Africa in particular has reported 120576 cases and total CFR of $0.2 \%$. A Quarter of million cases have been reported within a period of two years and 2860 people died as a result during that period, bringing the average CFR of the entire continent at $1.21 \%$. This shows that at least 9 people die of cholera every day in sub Saharan Africa (252 people die every month).

\subsection{Cholera in the West Africa}

The WHO has reported a total of 10336 cholera cases in West Africa. 356 deaths have also been confirmed through different health ministries. Highest cases reported were in Chad with 3556 cases and Corte de I'voir with 3152 cases reported. Although 175 cases of death have been reported in Corte de I'voir, the highest CFR was in Guinea with $8.0 \%$, where only 155 cases have been reported. The lowest CFR was in Burkina Faso and Cameroon, with 1.9\%.

\subsection{Cholera in the Central Africa}

The Central African region has reported 75035 cholera cases to WHO during 2001- November 2002. Of those, 1478 resulted in death, bringing CFR to $1.96 \%$. Tanzania has the worst cholera outbreaks but their containment programme was highly intensified because the CFR stood at 2.79\% from 33211 case reported. The Democratic Republic of Congo had the highest CFR in central Africa, hitting 8.1\% with 407 deaths reported from 5021 cases.

\subsection{Cholera in the East African}

The Ministry of Health informed the WHO in countries of Eastern Africa of an increase in cholera cases and deaths. The situation was similar to that at the end of 1997 when almost all countries in the Horn of Africa were affected by severe cholera outbreaks. Most of the countries then affected continued to report cases of cholera to WHO throughout 1998. However, sudden increases in cases and deaths are now being reported in the same area.

3701 cholera cases have been reported in West Africa. Only 172 deaths have been confirmed and the CFR was $4.64 \%$. Somalia has reported 2487 cases and the CFR stood at $6.35 \%$, registering the highest case fatality rate in the East African component. 


\subsection{Cholera in the Southern Africa}

Recent outbreaks of cholera in Southern Africa have also reached the highest proportions ever. A total of 154395 cases have been reported, with South Africa alone reporting 120567 cases. More than 50\% of cases reported in the entire continent have been reported in South Africa, however the lowest CFR of $0.2 \%$ in the continent has also been reported in South Africa. Kwazulu Natal Province had (in 2001) more than $90 \%$ of all cholera cases reported in South Africa [4]. Zimbabwe has reported 2124 cases and 8.0\% CFR. That made Zimbabwe to be the highest hit country in the region, considering the CFR.

The CFR of the entire component stood at $0.49 \%$, which was the lowest in the continent as compared to the other components. One can conclusively say that cholera outbreaks are best managed in Southern Africa. Reporting is also best in the region because of the infrastructure that is in place.

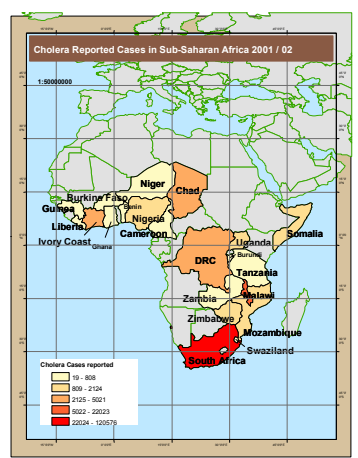

Figure 1: (a) Cholera reported cases in sub Saharan countries, 2001-
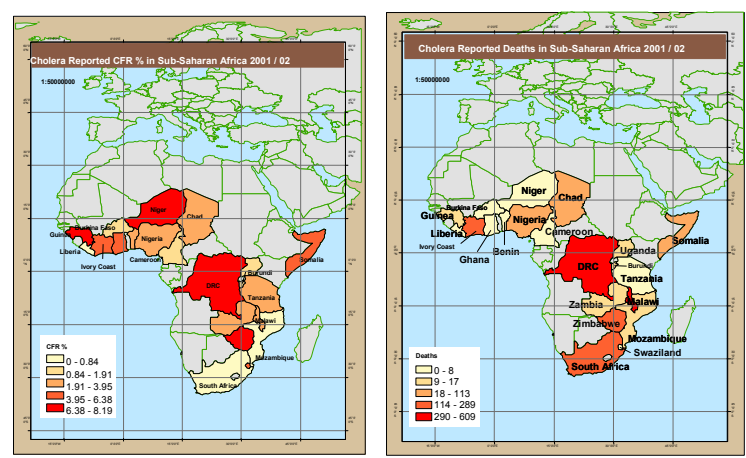
Nov.2002. (b) Cholera Case Fatality Rate in Sub Saharan Countries, 2001-Nov.2002. (c) Cholera reported death cases sub Saharan countries, 2001-Nov.2002.

\section{Factors influencing spread of cholera}

Cholera cases have not only been reported in Africa, but all over the world like India, Afghanistan and other countries. However, the severity and extent of outbreaks are sporadic and vulnerable in sub Saharan countries. Conditions attached to most countries also hit by cholera are by no means worse than the ones applying in sub Saharan countries. In most European and the Western countries, cholera cases are rare.

This then brings us to critical factors between these countries which the study has identified, that are common amongst sub Saharan countries, and contributing to further spread of cholera and other diarrhoeal diseases. 
Table 1: Cholera statistics in sub Saharan Africa as reported by the WHO, 2001- Nov. 2002.

\begin{tabular}{|l|c|c|c|}
\hline Country & Cholera cases & Death & cases \\
\hline & & & \\
\hline Benini & 165 & 6 & 3.64 \\
\hline Bukinafaso & 314 & 6 & 1.9 \\
\hline Burundi & 808 & 10 & 1.2 \\
\hline Cameroon & 158 & 3 & 1.9 \\
\hline Chad & 3557 & 113 & 3.2 \\
\hline Comoros & 1243 & 43 & 3.46 \\
\hline Corte d voir & 3152 & 175 & 1.9 \\
\hline DRC & 5021 & 407 & 8.1 \\
\hline Ghana & 47 & 3 & 6.38 \\
\hline Guinea & 155 & 12 & 8.0 \\
\hline Liberia & 661 & $\mathrm{~N} / \mathrm{A}$ & $\mathrm{N} / \mathrm{A}$ \\
\hline Malawi & 33211 & 926 & 2.79 \\
\hline Mozambique & 21339 & 287 & 3.65 \\
\hline Niger & 104 & 8 & 7.70 \\
\hline Nigeria & 2023 & 80 & 2.8 \\
\hline Somalia & 2487 & 158 & 6.35 \\
\hline South Africa & 120576 & 289 & 0.2 \\
\hline Swaziland & 19 & 1 & 5.26 \\
\hline Tanzania & 36464 & 133 & 3.65 \\
\hline Uganda & 1214 & 14 & 4.86 \\
\hline Zambia & 339 & 12 & 3.54 \\
\hline Zimbabwe & 2124 & 174 & 8.0 \\
\hline Cumulative Total & $\mathbf{2 3 5 1 8 1}$ & $\mathbf{2 8 6 0}$ & $\mathbf{1 . 2}$ \\
\hline & & & \\
\hline
\end{tabular}

\subsection{Socio-economic living conditions (poverty)}

There is no single definition that can be all embracing in defining poverty. Different countries have their own scale of measuring poverty. This study therefore focused on the definition by the World Bank. The World Bank defines poverty as hunger or lack of food, lack of money and joblessness, lack of education, being powerless, lack of representation and freedom. The base line used to measure that is determined by the Purchasing Power Parity (PPP) of \$1 US Dollar per person per day. In 1999, 1,2 billion people in developing countries lived under \$1 US dollar per person per day. 300 million of them lived in sub Saharan countries. Among black people and families headed by women, poverty rates exceeded $35 \%$ [5].

Shortages of food impede growth and retard the human immune system. A person who lacks food is susceptible to different kind of diseases, including cholera. Report by the WHO, United States Center for Diseases Control (USCDC) on nutrition and population indicated that major percentage of people treated for diarrhoeal diseases, whose weight were between two to three standard deviation lower than median reference intended for their age, suffered from malnutrition [5]. Malnutrition conditions are vulnerable in sub Saharan Africa as most of the countries still depend on imports, donations and subsistence farming for food. 
In the year 2000 the US was ranked $3^{\text {rd }}$ richest economy in the world, based on its $\$ 34.100$ Gross National Income (GNI) per capita in PPP terms. By the same year WHO did not have any cholera and diarrhoeal disease outbreak statistics for the US. The country that was rated the poorest by that time in PPP terms was Sierra Lione with GNI of \$25 [5]. The very same year Sierra Lione has reported 3094 cases, 132 death and the CFR stood at 4.3\%. There are more people living far below poverty indices in sub Saharan countries. Over the last five years the average income for the richest twenty countries in the world was 15 times the average of the poorest country, now it has doubled. Cholera as well as other disease outbreaks and deaths have increased tremendously.

The level of education is another contributing aspect, which cannot be ignored. Of the 3.4 billion adults living in developing countries, 870 million of them live in sub Saharan Africa. One of every four of them cannot read or/and write. 110 million primary-school-age children in developing countries were not in school in 1998. Of these 66 million were girls. Considering 15-19 year olds from the poorest 40 percent of the population in Mali and Benin, the median number of years these teenagers have been to school was 0 years in 1998 [5]. Having the illiterate levels we have, it becomes a difficult task to teach people about cholera and other diseases, as one had to depend solely on oral communication.

However one of the Millennium International Development Goals is to call for universal primary enrolment by 2015. The world through the World Summit on Sustainable Development (WSSD) Conference, which was held in Johannesburg in 2002, and the Agenda 21 have also agreed to halve the number of people living in poverty and without clean water by 2015. South Africa is committed to halve that by 2008. This could be a major development in the history of poverty.

\subsection{Lack of proper water supply and sanitation}

Water is a scarce resource in Africa. A team of researchers at Britain's Center for Ecology and Hydrology as well as experts from the World Water Council developed a new Water Poverty Index to highlight the differences between water-rich and water-poor nations. Out of a total of 147 countries, it ranks Finland top followed by Canada, Iceland, Norway, Guyana, Suriname, Austria, Ireland, Sweden and Switzerland. At the bottom end of the scale, Haiti lies at 147 th, preceded by Niger, Ethiopia, Eritrea, Malawi, Djibouti, Chad, Benin, Rwanda and Burundi [6].

Lack of clean water and sanitation is the main reason disease transmitted by feces are so common in developing countries. Nearly three-quarters of the world's poor live in rural areas where there is no proper water supply and sanitation. Estimates suggest that 3 billion people lack adequate sanitation. The numbers are continuing to rise due to population growth and other factors. The results is that more than 1 billion cases of diarrhoeal diseases are reported per year and an estimated 10000 people who die every day from water-related diseases. 
Sanitation includes interventions to reduce people's exposure to diseases by providing a clean environment in which to live with measures to break the cycle of disease. This usually includes disposing of, or hygienic management of, human and animal excreta, refuse and wastewater, the control of disease vectors and the provision of washing facilities for personal and domestic hygiene. Poor hygiene and sanitation take a particularly high toll on children. Diarrhea accounts for about a third of total children deaths under the age of five in sub Saharan Africa.

The World Bank encourages its borrower to recover, at a minimum, operation and maintenance costs of water and sanitation through tariff revenues, in order to make the investments sustainable. This notion has promoted people, who are financially disadvantaged to resort to other sources of water, some of which were cholera heavens (mostly surface water which is relatively cheap to access). In trying to address this the South African government has introduced free basic water (6000 $l$ per month per household) to poor households. Latest updates indicate that 26,167,485 people are served with basic free water in South Africa. However not all municipalities are able to provide the service at the moment due to infrastructure development. The excellent sanitation facilities in the US are responsible for the near eradication of epidemic cholera. Sporadic cases occurred when shellfish harvested from previously faecally-polluted coastal water were consumed raw and international commuting from previously affected areas.

\subsection{Lack of access to health care and medical facilities}

Another major contributing factors to the spread of cholera are lack of access to health care and medical facilities, poor infrastructure development and under developed primary health care systems. Musanya, from Zambia has been quoted many times saying, "Each day there is a funeral in nearby village because of distance to the hospital". Although other reasons are also linked, the number of cholera death cases in this study also qualifies the authenticity of that statement. Primary health care is the pillar of health care services as it also promotes basic hygiene principles.

In the United States, between 1990 and 1998, 8 women died for every 100,000 live births. While in Democratic Republic of Congo (DRC) and Eritrea, 1,000 women died for every 100,00 live birth. In 1970, in the developing world, 110 infants died per 1,000 live births, while 58 infants died in 2000 per 1,000 live births. Between 1988 and 1998, in the developing world, 32 boys out of 1,000 died between the ages of one and five. The figure for girls was 48 . While life expectancy in the developing world increased from 60 years in 1980 to 64 years in 2000, in Botswana it was reduced from 58 years in 1980 to 39 in the year 2000 [7]. These statistics are clear indication that inadequate health systems are contributing factors to high death tolls in sub Saharan Africa. That is the reason why many health and welfare organization like the Red (Cross) Crescent, USAID, UNICEF, etc. are involved in sub Saharan countries.

It is primarily the rural population and the population in the informal urban sectors that are financially excluded from protection against disease. For those reason many rural people rely on conventional ways of treating diseases rather 
than sending them to hospitals. Many people die in the process because of lack of expertise and training. Other population groups pay for health treatment mainly through solidarity structures based on family or ethnic allegiances. The members of these family or ethnic groups help each other mutually from pool resources when one of their members is in (financial) need. The problem is that private, commercial health insurance organizations exclude these two segments of the population from their services, as they are not regarded as being financially "solvent".

In order to provide protection against the financial effects of health risks, a few European countries at the end of the 19th century introduced health insurance systems for workers (e.g. in Germany between 1883 and 1889). In sub Saharan countries, social insurance is still confined to a minority of the population, e.g. through contributions to pension and health insurance funds that are directly deducted from the pay. This minority mainly consists of state employees, members of the armed forces, and employees of large companies. According to a World Bank study in 1987, at the end of the 1980s only seven of 33 sub Saharan African countries studied had a health insurance system. In these seven countries, the proportions of the population with health insurance ranged at that time from only $0.001 \%$ in Ethiopia to $11.4 \%$ in Kenya [8].

In Senegal, Mali, Burkina Faso, and Ghana, considerable experience in the setting up of health insurance organizations has been gained. There are several examples of health insurance organizations, for example the so-called mutuelles de santé in Thiès near Dakar in Senegal. Sixteen local health insurance organizations have been in existence there since the early 1990s, cooperating closely with the Saint Jean de Dieu regional hospital. In this case, the health insurance organizations pay for $100 \%$ of hospital costs for 15 days, while the hospital offers their members a $50 \%$ reduction on normal cost [9].

Poorly developed infrastructure hinders communication as disease outbreak goes without being reported. This study has also found that some cholera outbreaks were not reported due to communication breakdown.

\section{Recommendations}

- Although the critical factors highlighted above can be addressed to eradicate cholera and other related diseases, promotion of basic hygiene practices, e.g. The South African "WASH" Campaign, remains the main solution that can reduce the number of infections by greater percentage.

- Participatory improvement of water supply and sanitation for sustainable development.

- Experience with successful projects suggests set of basic principles to guide the design of rural water and sanitation intervention e.g. Involvement of local stakeholders.

- Intensify health awareness e.g. Cholera Champaign and Health Education in general.

- Raise literacy and adult basic education standards.

- Sustainable implementation and continuous research for sustainable poverty alleviation strategies. 


\section{Conclusions}

A lot of work with regard to cholera eradication has been done and well documented in papers, government policies, etc. Until such time that policies and guidelines are implemented successfully, people will continue to die of cholera and other diseases. Many social and welfare organizations are working tirelessly to monitor, report and give assistance whenever there are cholera outbreaks. It is also of significant importance that each person should take individual effort to combat further spread of cholera.

\section{Acknowledgements}

The author would like to acknowledge efforts put by Dr. Phillip Kempster and Mr Mbangiseni Nepfumbada for their scientific guidance in this study. Mr. Brandon Hohls for proof reading this paper. My sincere gratitude goes to Mr. Axel Diefenbach for helping the author on Geographic Information System (GIS) map projections. The author wants to acknowledge Harold Van Niekerk, for his encouragement to do this study.

The author also wants to acknowledge the following organizations: WHO, for supplying most of the data and The Department of Health, Kwazulu Natal (RSA), for their daily updates on cholera outbreaks.

\section{References}

[1] Cloete, T.E., Principles of Microbiology, University of Pretoria: South Africa, 2002.

[2] http://www.WHO.int/Health_topic/en. UK, 2002.

[3] Department of Water Affairs and Forestry, Guidelines for the Management of waterborne Epidemics, with the Emphasis on Cholera Co-ordination, Communication, Action and Monitoring, Edition 1, Pretoria: South Africa, 2001.

[4] Mugero, C, (Dr) \& Hoque A.K.M. (Dr), Review of Cholera Epidemic in South Africa, with focus to Kwazulu Natal Province, South Africa, 2001.

[5] World Bank, World Bank Statistical Information Management and Analysis (SIMA), 1998.

[6] http://www.planetark.org/dailynewsstory.cfm/newsid/19300/story.htm, UK, 2002

[7] World Bank, Global Economic Prospects in the developing countries, 2001.

[8] Dror, D. \& Christian J., Micro-Insurance: Extending Health Insurance to the Excluded (Geneva: Social Security Department, ILO Planning, Development and Standard Branch), pp. 2-3, 2002.

[9] Johannes, J. \& Justin T., Micro Insurance Scheme and Health Care Provision in Developing Countries, Bonn, 2001. 